\title{
Una aproximación ecológica al estanco de tabaco en la Sierra de Zongolica, Veracruz, 1767-1812.
}

\author{
Morales Vázquez, Edwin Alberto \\ Universidad Veracruzana, México \\ moralesvazquezedwin@gmail.com
}

Resumen - Este trabajo es un primer acercamiento a las consecuencias ecológicas provocadas por el cultivo del tabaco en la Sierra de Zongolica entre 1767 y 1812 . Como resultado de este ejercicio se encontró que, en la región se transitó de una agricultura de autoconsumo a una comercial, a finales del siglo XVIII, lo que provocó deforestación y erosión de suelos. La pertinencia de este trabajo radica en que, actualmente es necesario el análisis histórico de los procesos que influyen en los desastres naturales.

Palabras claves - El estanco del tabaco; reconversión agrícola; explotación de recursos naturales; paisaje mesoamericano; paisaje rural; deforestación y erosión;

Abstract - This paper is a first approach to the ecological consequences caused by the cultivation of tobacco in the Sierra de Zongolica between 1767 and 1812. As a result of this exercise, it was found that, in the region, there was a transition from self-consumption to commercial agriculture at the end of the 18 th century, which caused defores- tation and soil erosion. The relevance of this work lies in the fact that, at present, a historical analysis of the processes that influence natural disasters is necessary.

Keywords - The tobacco monopoly; agricultural reconversion; exploitation of natural resources; Mesoamerican landscape; rural landscape; deforestation and erosion;

\section{INTRODUCCIÓN.}

De acuerdo con Boege (2008), la Sierra de Zongolica hoy en día es una región de interés ambiental porque, "funciona como reservorio de una amplia variedad de especies de flora y fauna, casi extintas y otras que hasta hace poco estaban sin clasificar" (324-325), además con sus menguados bosques aún funge como un pulmón para el actual complejo agroindustrial Córdoba-Orizaba. 
El artículo abarca el período 1767-1812, el cual inicia con las Reformas Borbónicas, una serie de cambios administrativos como "el estanco del tabaco", que propició cierta bonanza económica en algunas regiones de la Nueva España, y concluye con la rebelión de los habitantes de Zongolica contra el poder virreinal, en abril de 1812, cuando los sembradores quemaron la cosecha del tabaco y abandonaron los ranchos donde se secaba "la preciosa hoja".

En la revisión bibliográfica a Orizaba y Zongolica, se encontraron diversas líneas temáticas como demografía, urbanismo, comunicaciones, tenencia de la tierra, reparto del trabajo indígena y el monopolio del tabaco. Sin embargo, no se ha analizado al "estanco del tabaco" desde la perspectiva ecológica, de ahí el interés por un acercamiento al monopolio con un enfoque ambiental centrado en la explotación de la tierra y la pérdida de bosques $^{1}$.
La perspectiva ambiental es una categoría de análisis que enriquece la investigación histórica, como lo demuestran las aportaciones de Funes (2002), Gallini (2002), Soluri (2013), por referir algunas investigaciones. En México, la historia ambiental ha tenido un desarrollo notable, ejemplo de ello son los trabajos coordinados por García y González (1999) y Tortolero (1996), donde se analizan los procesos históricos que incidieron en fenómenos como deforestación, inundaciones, sequías y empobrecimiento de suelos. Es en este tenor en el que se inserta el trabajo que el lector tiene en sus manos.

A partir de 1767, con la siembra del tabaco en el pueblo de Zongolica, la sierra del mismo nombre se integró a uno de los monopolios comerciales más productivos de la corona española. Ante tal situación surgen un par de preguntas ¿De qué manera incidió el cultivo de la solanácea en la agricultura de autoconsumo en la Sierra de Zongolica?, ¿Cuáles fueron las

1 En lo relativo a la villa de Orizaba, revisar: Ribera, 2002; Valle, 2008; Valle, 1996; Valle, 1993. Por lo que concierne al pueblo de San Francisco Zongolica, consúltese: Aguirre, 1995; Rodríguez, 2003. 
Una aproximación ecológica al estanco de tabaco en la Sierra de Zongolica, Veracruz...

transformaciones ecológicas provocadas por la siembra del cultivo comercial?

La hipótesis que se propone es, la siembra del tabaco en la zona cálida de la Sierra de Zongolica supuso el tránsito de un entorno de autoconsumo a uno donde coexistió una menguada agricultura de autoconsumo con un monocultivo intensivo. De ese modo, la siembra intensiva del tabaco conllevó a que ciertas extensiones de bosques y milpas se convirtieran en tierras de cultivo intensivo, lo que transformó de forma decisiva el uso de suelo en la región, de tal suerte que distintas áreas de bosques dieron paso a campos de monocultivo intenso que con los años cedieron su lugar a matorrales y posteriormente a pastizales.

La bibliografía revisada para esta investigación se complementa con un sustento documental de primera mano, consultado en distintos fondos entre los que destacan "México" así como "Mapas y Planos" del Archivo General de Indias (AGI) además de los fondos "Archivo Histórico de Hacienda", "Indios",
"Tabaco", "Tierras" y "Tributos" del Archivo General de la Nación (AGN) enriquecidos por los registros de diversos años resguardados en el Archivo Notarial de Orizaba (ANO).

El texto se ha estructurado en cuatro apartados. En el primero, se reconstruye el agroecosistema de la Sierra de Zongolica, la idea de un agroecosistema se ha retomado del modelo de regionalización propuesto por Ponce y Cerda (1981: 41-69), en el cual se entretejen aspectos geográficos, políticos y económicos. En el segundo, se señalan los elementos económicos y mecanismos políticos que permitieron la articulación comercial y financiera entre un "pueblo de indios" como Zongolica y un asentamiento español, la villa de Orizaba que fungía como centro regional redistribuidor de mercancías y ganancias. En el tercero se revisan las consecuencias ambientales producidas por la introducción de la siembra del tabaco -un cultivo comercial- a tierras donde había bosques y milpas para el autoconsumo. Finalmente, en el cuarto apartado se exponen un balance y se esta- 
blecen las conclusiones de la investigación.

LA REPÚBLICA DE INDIOS EN

\section{LA SIERRA DE ZONGOLICA.}

La Sierra de Zongolica fue incorporada a la corona de Castilla en 1598, cuando se agregó a la alcaldía mayor de Veracruz Vieja con sede en el pueblo de La Antigua, en 1786 la alcaldía fue reorganizada como una subdelegación, la cual en 1804 se anexó a la jurisdicción de Orizaba a la que perteneció hasta 1824.

De acuerdo con la documentación administrativa de la Monarquía Ibérica (AGI, México, vol. 1278, año 1781; AGI, vol. 1278, año 1782), los pueblos de la Sierra de Zongolica formaron parte de la "república de indios" de Zongolica cuya cabecera fue San Francisco Zongolica y sus "pueblos sujetos" fueron San Jerónimo Atzingo, Santa María Astacinga, San Andrés Coetzala, San Andrés Mixtla, Santos Reyes, San Martín Atlahuilco, Santa María Magdalena, Santiago Tehuipango, Texhuacán, Tlaquilpan y Xoxocotla; los cuales en conjunto llegaron a su- mar una extensión aproximada de 977 kilómetros cuadrados $\left(\mathrm{km}^{2}\right)$.

En aquel entonces, un "pueblo cabecera" ejercía funciones de gobierno civil, administración de justicia y hacienda. Conocedores de los beneficios de contar con un cabildo propio, los "pueblos sujetos" de Zongolica buscaron convertirse en cabeceras de sus repúblicas, hecho que para 1806 la mayoría había logrado excepto Santa María Astacinga (Tanck, 2005: 97, 200).

Durante el período de análisis, los asentamientos de la Sierra de Zongolica se comunicaron y comercializaron con los pueblos del Valle de Orizaba a través de senderos, veredas y caminos que, a continuación se describen. La primera vía seguía el rumbo de Los Reyes, Atlanca, San Andrés, Tilapa y Orizaba. La segunda posibilidad era pasar por San Sebastián para continuar por El Naranjal, El puente de Los Micos, San Juan del Río y la garita Esmeralda y Orizaba. En el camino entre el puente de Los Micos y el ingenio de Tuxpango se bifurcaba un ramal que iba hacia Magdalena para llegar a San 
Una aproximación ecológica al estanco de tabaco en la Sierra de Zongolica, Veracruz...

Andrés y proseguía por la primera vía descrita, la cual se constituía en una tercera alternativa. Finalmente, la cuarta ruta atravesaba por San Juan Atlanca, San Martín, San Pedro Tequila para arribar a San Andrés y continuar por Tilapa y seguir por la garita de Xalapilla y concluía en Orizaba (AGI, Mapas y Planos, vol. 750, año 1784, plano 1).

La villa de Orizaba a su vez era un punto estratégico en el sistema de las comunicaciones y el intercambio comercial de la Nueva España, ya que estaba asentada en uno de los ramales del otrora Camino Real que conectaba al puerto de Veracruz con la Ciudad de México, lo que le permitía a sus moradores abastecerse de alimentos, vestimenta, calzado, herramientas de trabajo, artículos suntuarios, mano de obra, así como prestar servicios de hospedaje sin olvidar el transporte de carga y pasajeros (AGN, Indios, vol. 60, exp. 193, año 1806).

Estudiar el medio ambiente o los factores geográficos y ecológicos, permite reflexionar y comprender la historicidad de las relaciones y las influencias mutuas entre los hombres y la naturaleza; las cuales se cristalizan en las formas que los seres humanos han manejado los recursos naturales, creado cultura material y su cosmovisión como un acto de comprensión propia (Watsuji, 2006: 29-36). A continuación, se describe el medio geofísico en el que se desarrolló la interacción motivo del presente estudio.

El espacio donde convergen la Sierra Madre Oriental y la Sierra Madre del Sur, en el estado de Veracruz recibe el nombre de la Sierra de Zongolica, la cual tiene la forma de una intrincada cadena de cerros altos, profundas barrancas, escarpadas laderas y pequeños valles. Al norte limita con el pico de Orizaba y el cañón del río Blanco, al sur con la Sierra Mazateca y la Sierra Negra entre los estados de Oaxaca y Puebla, al oeste con la llanura costera del Golfo de México y al este con el valle semidesértico de Tehuacán en el estado de Puebla (Rodríguez, 2010: 70).

El conjunto de sus cerros forma una parte inclinada que en dirección oeste-este desciende de una 
altura aproximada de 3,000 metros sobre el nivel del mar (msnm) pasan por los 1,800 msnm hasta llegar a la planicie costera donde el relieve se suaviza. Mientras que su sistema fluvial está constituido por un complejo de corrientes de curso corto, comprendido entre las subcuencas del río Blanco y del río Salado, que a su vez son afluentes de la cuenca del río Papaloapan que desemboca en la laguna de Alvarado para finalmente desaguar en el Golfo de México (García, 2000: 43).

Las corrientes fluviales recorren la escabrosa topografía de la Sierra de Zongolica, comienzan su vertiginoso descenso por cañadas, barrancas y laderas; socavan las formaciones calcáreas para sumirse en sus fondos y continuar su recorrido por túneles que atraviesan las montañas y reaparecen en forma de cascadas. En la opinión de González(s/f.), estas cañadas, barrancas y laderas en las zonas montañosas son propicias para la siembra de cultivos tropicales como el tabaco.

Islas (1990:9), sostienen que a causa de dos diferentes masas de aires -tropical y polar- las lluvias son frecuentes y abundantes en la Sierra de Zongolica. El viento tropical, en los meses de junio a septiembre provoca las lluvias más copiosas del año -verano y otoñoen tanto que la corriente polar trae consigo la niebla y el invierno durante los meses de febrero a mayo, cuando se presenta el tiempo de seca. A consecuencia de las condiciones descritas, la precipitación anual ahí fluctúa entre los 2,000 y los 2,500 milímetros $(\mathrm{mm})$ y su temperatura promedio anual oscila entre los 15 y los 20 grados Celsius $\left({ }^{\circ} \mathrm{C}\right)$. Los registros administrativos novohispanos informan que en mayo de 1771 se presentó en la región una lluvia torrencial provocada por un fuerte huracán que ese año dejó como resultado la pérdida de la cosecha del tabaco (AGN, Tabaco, vol. 455 , exp. $s / n)$.

Debido a su variada orografía, así como a su régimen de lluvias y de temperaturas en la Sierra de Zongolica existen tres diferentes climas. El clima frío se presenta a una altura que oscila entre los 3,000 y los $2,600 \mathrm{msnm}$, el clima templado está presente en la zona media que va de los 2,600 a los 
1,500 msnm y el clima tropical se experimenta en la zona cálida que desciende de los 1,500 a los 500 msnm. De acuerdo con Álvarez y Rodríguez (1992), "tanto los fenómenos climatológicos como los tipos de suelos, han propiciado que esta sierra goce de la prodigalidad manifiesta en sus perenes bosques de coníferas" (159-160).

En esta región el tipo de suelo arcilloso es el común, mientras que en la cabecera de la "república de indios" San Francisco Zongolica el tipo de suelo predominante es el luvisol. Aunque en diferentes áreas de esta sierra, se pueden encontrar suelos de los tipos andosol, foezoem y fluvisol.

La siembra del tabaco específicamente requiere de alturas que van desde el nivel del mar hasta los $700 \mathrm{msnm}$, temperatura promedios anuales que oscilan entre los 18 y los $28{ }^{\circ} \mathrm{C}$, precipitaciones medias de alrededor de los $1,200 \mathrm{~mm}$, así como de suelos con buen drenaje y ligeramente alcalinos. Al contrastar los datos de las condiciones fisiográficas que demanda la siembra del tabaco con las características de cada uno de los nichos ecológicos que integran a la Sierra de Zongolica se percibe que, fue en la zona cálida de clima tropical de esta sierra donde el cultivo de la solanácea se adaptó.

\section{LA ARTICULACIÓN COMERCIAL}

\section{Y FINANCIERA MEDIANTE EL}

\section{ESTANCO DE TABACO.}

En este apartado se describe cómo la fuerza de trabajo indígena y los recursos naturales fueron los elementos que posibilitaron la articulación comercial y financiera entre el pueblo de Zongolica y la villa de Orizaba, es decir, la incorporación de un "pueblo de indios" al sistema económico del imperio español mediante mecanismos como la recaudación del tributo y el repartimiento de mercancías. Es oportuno recordar que, el tributo fue el principal movilizador de la empresa colonizadora en tanto que, el reparto de mercancías permitió a la población española acceder a materias primas y productos de los indígenas mientras que, los comerciantes y los "naturales de estas tierras" obtuvieron recursos económicos; los primeros para acrecentar sus 
ganancias y los segundos para pagar sus tributos (Menegus, 1995: 136-157; Pietschmann, 1992:117118).

Sin embargo, el mecanismo que produjo la mayor vinculación entre Zongolica y el sistema económico del imperio español, a través de la villa de Orizaba, fue el estanco de la siembra del tabaco. Debido a su funcionamiento este monopolio se desarrolló entre el tradicionalismo y la modernidad, ya que formó parte de una política económica que, por un lado, intentaba modernizar la administración imperial española para obtener resultados favorables en su balanza comercial y el fomento industrial; por lo que "el estanco del tabaco" es considerado un ajuste productivo dentro del proceso denominado Reformas Borbónicas. Por otro lado, fue una reestructuración tradicionalista tendente al acaparamiento de los beneficios del comercio ultramarino de la monarquía hispánica, con ello se intentaba reforzar la condición de súbditos de los habitantes de las Indias de Castilla (Martínez y Ludlow, 2007: 2023; Juárez, 2005: 25-26).
Las razones por las que la "república de indios" de Zongolica fue incluida en este monopolio comercial fueron varias, pero destacan la intención del cabildo de Orizaba de mantener su zona de influencia - Ixtaczoquitlán, El Naranjal, Tecamalu$\mathrm{ca}$, entre otros- como proveedora de alimentos -habas, chicharos, tomates, ciruelas, duraznos- y aprovechar las ventajas de la relativa cercanía de la Sierra de Zongolica cuyo acceso era más restringido que el de otras poblaciones de la intendencia de Veracruz y con ello tratar de evitar el contrabando además, claro, para beneficiarse de las cosechas que se pudieran levantar en las tierras que ofrecían las barrancas y cañadas de la región.

Se ha llegado a afirmar que, la hoja cosechada en la zona centro del actual estado de Veracruz resultó un producto de buena calidad por lo que la Real Renta de Tabaco, hizo pedidos cada vez más crecientes a los cosecheros de CórdobaOrizaba. Tal situación es comprensible si se considera que en la Nueva España solamente las villas de Orizaba y Córdoba, así como los pueblos de Huatusco y Zongolica 
Una aproximación ecológica al estanco de tabaco en la Sierra de Zongolica, Veracruz...

eran los productores autorizados para abastecer de la solanácea a las fábricas de Orizaba, Puebla, Oaxaca, Querétaro, Guanajuato, Guadalajara y la Ciudad de México; donde se producian cigarros y puros que se comercializaban a través de una extensa red de estanquillos extendidos hasta los puntos más alejados del virreinato como Saltillo (AGN, Tabaco, vol. 455, exp. s/n, año 1809).

Para ilustrar la idea de la dinámica articulación comercial y financiera entre la villa de Orizaba y el pueblo de Zongolica, se recurre a algunas cifras. Por ejemplo, en la década de 1790 en la Sierra de Zongolica había 867 agricultores indígenas que eran habilitados por 17 cosecheros de la villa de Orizaba a quienes en los tiempos de mayor producción les llegaron a entregar hasta 5,000 tercios de hojas secas que fueron vendidos en 312,500 pesos de ocho reales (ANO, año 1790). Para tener una idea clara de la cantidad de tabaco entregada a los cosecheros de Orizaba, es necesario precisar que un tercio se formaba con 80 manojos y cada manojo pesaba dos libras y medias (Aguirre, 1995: 85-87).
Mientras tanto en los almacenes, el pago del producto se realizaba de acuerdo con una estricta clasificación en la que la libra de primera clase valía tres reales, la libra de segunda clase costaba dos reales, la libra de tercera clase se pagaba a un real, la arroba de punta tuvo un valor promedio de 19 reales en tanto que el precio de la libra escogida de punta fina osciló entre un real y medio y dos reales (Silvestre, 2004: 27-33).

Para intentar explicar un poco más la articulación comercial y financiera entre Zongolica y Orizaba, es decir, de la economía del tabaco en un pueblo de indios con el orden colonial español es necesario considerar el contexto bélico en el que se enmarcó el período 1767-1812, ya que la corona española, en esos años sostenía guerras contra ciertas potencias europeas tanto en el viejo continente como en el mar Caribe y además tuvo que enfrentar la insurgencia novohispana. Este ambiente de guerra tuvo tal importancia que incidió en la modificación de la política impositiva en la Nueva España, la cual a finales del siglo XVIII pasó de una recaudación 
sobre la producción, el consumo y el tributo a la extracción de préstamos forzosos y la miscelánea de guerra (Aguirre, 1995: 85-87; Silvestre, 2004: 27-33).

La atmosfera bélica llevó a establecer, por un lado, el llamado "modelo borbónico de defensa militar" que requirió la remodelación de las fortificaciones, la instalación de baterías y la reorganización de los batallones en el amplio Circuncaribe que va desde la Florida hasta las Guayanas (Ortiz, 2006: 13-15; Grafenstein, 2001: 185-186). Además, entre 1764 y 1810, los elementos efectivos del ejército y la armada en la Nueva España pasaron de 6,000 a 22,277-distribuidos principalmente en la Ciudad de México, Puebla y el puerto de Veracruz- los cuales recibieron constantemente instrucción en el manejo de armas y la organización de milicias. En el caso del actual litoral veracruzano, el batallón de lanceros fue organizado entre 1762 y 1780 para resistir algún ataque eventual de Inglaterra o de los piratas (Galland, 2005: 217-218; McFarlane, 2008: 232-236).
Por otro lado, el contexto de confrontación incidió para que se reforzara la política fiscal de recaudación que Jáuregui (1993), ha denominado "mercantilista de corte liberal", mediante la cual la corona española buscó hacer eficiente la fiscalización en sus reinos, al intentar que "los administradores de las rentas monopólicas fueran funcionarios y no usufructuarios tanto del erario metropolitano como del indiano" (364).

Por su parte, los cosecheros orizabeños entre 1802 y 1811 contribuyeron a las campañas militares de la corona española, tanto en Europa como en el Caribe y en la Nueva España, con aportaciones de dinero producto de la venta de "la preciosa hoja" cultivada en su zona de influencia entre la que se encontraba la Sierra de Zongolica. El financiamiento de los cosecheros orizabeños se ha encontrado en contribuciones al enfrentamiento naval entre España e Inglaterra en 1802, para la defensa de la península ibérica contra la invasión napoleónica de 1808 así como para pertrechar al regimiento de patriotas que defendía a Orizaba y en la construcción de fosos a las afueras 
de su villa, durante la guerra por la independencia novohispana (Silvestre, 2004: 110-121).

\section{CAMBios EN EL RITMO DE} PRODUCCIÓN Y TRANSFORMACIONES EN EL PAISAJE.

Los pueblos congregados como los de la Sierra de Zongolica se organizaron a partir de un centro, constituido por una parroquia y una casa de comunidad, en torno a dicho centro como a lo largo del camino principal y alrededor de los cerros que rodeaban sus valles, se edificaron las viviendas de los habitantes de las congregaciones. El espacio doméstico en estos pueblos solía integrarse por una vivienda con su milpa y un pequeño huerto, y algunas veces incluía un gallinero y un corral para cerdos (Rodríguez, 1993: 63).

El tipo de agricultura que se practicaba ahí, era el de tumba y quema, el cual consistía en segar árboles y maleza para dejarlos secar y unos días después quemarlos y con sus cenizas abonar la tierra. Este proceso se podía repetir en un mismo lugar durante dos o tres años después hasta que sus rendimientos se redujeran y se buscaba un nuevo lote para desmontar, 10 o incluso 20 años después se regresaba a la fracción inicial cuando había recuperado su fertilidad (Rojas, 1988: 67).

Las siembras, usualmente eran de asociación y rotación o de coexistencia lo que redundaba en beneficios para la cosecha. Por ejemplo, el frijol como las demás leguminosas se utilizaba para fijar nitrógeno al suelo e incluso si era de una variedad de enredadera proporcionaba sombra a las milpas. Las calabazas, al cubrir el suelo con sus hojas y guías lo protegía del deslave de las lluvias y del acumulamiento excesivo de agua además de minimizar la evaporación y evitar el nacimiento de hierbas no deseadas (Rojas, 1988: 89-91).

Antes del monopolio de su cultivo y comercialización, el tabaco era utilizado en diferentes formas, ya fuera como medicina o elemento ritual. Su utilidad como medicamento fue reseñada tanto por cronistas de la época en que la hoja se convirtió 
en una moda y un vicio para los europeos; como por renombrados historiadores de hoy en día. Aquí se consideran las descripciones tanto de un funcionario del monopolio del tabaco como de como de un historiador.

El primero registró que con dicha hoja se elaboraban tónicos para curar la tos, la pleuritis, los cólicos, la disentería, la ictericia, la hidropesía, la sarna, la tiña además de emplearse como repelente (Quiroga, 1779: 6-7). El segundo anotó que la hoja era de utilidad como laxante, purgante, vomitiva, desinfectante de mordidas de serpiente y heridas (Céspedes, 1992: 20). Hoy también se sabe que era ofrendada a los dioses en rituales durante la inauguración de los templos o en aniversarios luctuosos de los señores principales.

A finales del siglo XVIII, humear ya fuera con cigarros en los cuarteles, las calles y las plazas o con pipas en los paseos, los cafés, los teatros y los palacios se había convertido en una "manía estilizada". Para mantener este amplio consumo, en la Sierra de Zongolica se llegó a producir un tercio del total del tabaco comercializado en la Nueva España. Sin embargo, para producir tan elevada cantidad de la solanácea, fue necesario que se realizaran importantes cambios en la dinámica de trabajo y por consiguiente en el paisaje de la región.

Los habitantes de la Sierra de Zongolica como parte del área cultural de Mesoamérica, asociaron la agricultura con una fascinante concepción del mundo y sus dioses, por lo que antes de sembrar pedían perdón a la tierra por arañarla con los instrumentos de cultivo para despojarla de su ropa -la vegetación- y quemar su carne. Dicho ritual obedecía a la creencia de los pueblos indígenas que se consideraban solamente huéspedes de la tierra y no sus dueños (Paso, 1988: 99).

La transformación en la forma de concebir al tabaco, de una planta medicinal y elemento ritual a un producto lucrativo, modificó la práctica agrícola de los pueblos de la Sierra de Zongolica, quienes en el último tercio del siglo XVIII experimentaron estrictos requerimientos 
como lo fueron: el cumplimiento de un horario y una carga de trabajo que impedían la realización de ciertos rituales tradicionales. Además, la agricultura de rotación o coexistencia que desarrollaron hasta antes del establecimiento del "estanco del tabaco" fue sustituida por un monocultivo intenso (ANO, año 1792).

Entre los notables cambios que se encontraron en las condiciones de producción destacan, el establecimiento de veedores que vigilaban que los trabajadores cumplieran con sus horarios y cargas laborales sin perder de vista la construcción de pequeños establecimientos Ilamados ranchos para orear y secar la hoja que era remitida a la Real Renta de Tabaco. Incluso en las fuentes documentales existen registros que cerca de los campos de cultivo del tabaco se levantaron pequeñas construcciones llamadas "casas tabaqueras" en las que habitaban "levantadores" quienes ahí oreaban y secaban la hoja para después enviarla a Orizaba (ANO, año 1776). Actualmente se especula que estas "casas tabaqueras" pudieron ser los primeros asentamientos de población no indígena en la Sierra de Zongolica y que posteriormente dieran paso a la constante llegada de mestizos e incluso criollos a la región.

Otro de los cambios importantes que trajo el monopolio del tabaco a la Sierra de Zongolica, fue que sus habitantes ya no fueran repartidos como mano de obra en el ingenio de Oztotitpac sino que se emplearan como labradores en sus pueblos y recibieran un pago que podría consistir en dos reales y medio por día o dos reales diarios acompañados por una ración de comida compuesta por frijoles, tortillas y chiles (AGN, Tabaco, vol. 466, exp. s/n; AGN, Tabaco, vol. 455, exp. s/n).

A cambio del pago, las tareas a desempeñar comúnmente consistían en talar árboles, desmontar terrenos, quemar maleza, hacer surcos y canales a mediados de junio, trasplantar la solanácea de los almácigos a los surcos a finales de agosto. Posteriormente abonar y limpiar los cultivos, así como levantar la cosecha a finales de octubre y principios de noviembre (Aguirre, 1995: 123). 
Antes del intenso monocultivo del tabaco, en la Sierra de Zongolica imperaba un "paisaje mesoamericano", integrado según Whitmore (2003:73) por milpas y huertas, donde primaba una agricultura de autoconsumo de la que se obtenía maíz, frijol, calabaza y chile. Con el establecimiento de un monocultivo intenso se inició la formación de lo que para fines de este trabajo se ha llamado "un paisaje rural" en el que coexistieron la milpa, la huerta y un campo de cultivo comercial.

Algunos versados en la historia ambiental como Melville (1994) y Hernández (2001), consideran que la agricultura no ha resultado tan dañina ni tan depredadora de los recursos naturales como la ganadería. Sin embargo, cuando se revisa detenidamente el impacto ambiental y las transformaciones producidas por la agricultura comercial se observa que esta última ha provocado cambios ecológicos considerables.

En el caso de la "república de indios" de Zongolica, se encontró que el cabildo del "pueblo cabecera", rentaba a los cosecheros de Oriza- ba ciertos ejidos y diversas dehesas de los pueblos de su jurisdicción para el cultivo de "la preciosa hoja" y de ese modo obtener beneficios económicos que eran resguardados y administrados desde la caja de la comunidad. No está demás enfatizar que se considera que las barrancas y las cañadas ubicadas en los ejidos y las dehesas de la zona cálida fueron los sitios idóneos, para la siembra de la solanácea por contar con tierras fértiles en pendientes que permitían liberarse de las inundaciones $y$ aprovechar la humedad del aire (AGN, Tierras, vol. 455, exp. s/n; AGN, Archivo Histórico de Hacienda, vol. 581, exp. 6).

Por ahora se cuentan con algunos relatos que refieren más de una veintena de parajes de la zona cálida de la Sierra de Zongolica donde se sembraba esta valiosa hoja $y$, además, se señala que en su totalidad estos ranchos abarcaban una extensión de dos sitios de ganado menor, es decir, 1,560 hectáreas, si se considera que cada sitio de ganado menor tenía una extensión de 780 hectáreas. Tales ranchos o parajes eran: Ametepec, Capoluca, 
Coyametla, Palapa, Paloquautla, Papalocuatla, Puente de los micos, Tecolotla, Tequistlaca, Texisapa, Tlacotlapa, Tlahuistlapa, Tlanespaquilla, Tlasolapa, Tonalapa, Tonalixco, Tuzpango, Yaxtlamoyola, Zapuapa, Zoxhitla y Zocuautla (Reyes, 1962: 83; Quiroga, 1779: 38).

Los contratos establecidos entre los cosecheros y sus agricultores, proporcionan información que complementa los datos obtenidos en los relatos. Por ejemplo, en tales contratos se especificó que las áreas de cultivo tabacalero en los ranchos de la zona cálida de la Sierra de Zongolica contaron con una superficie promedio de ocho hectáreas en los que se requería el trabajo de alrededor 10 personas (ANO, 1790; AGN, Tabacao, vol. 44).

La dimensión de 1,560 hectáreas puede parecer menor si se compara con la cantidad de hectáreas que en la actualidad se talan, desmontan y siniestran. Sin embargo, para aquella época representaron una transformación ecológica que cambió el paisaje al talar los bosques y desgastar la capa vegetal de las tierras de cultivo en las que antes se practicaba una agricultura de rotación e incluso incidió en la reducción del cultivo de alimentos que se consumían en la Sierra de Zongolica.

Como consecuencia de la reconversión agrícola y por ende del cambio en el uso del suelo, a lo largo del período aquí revisado, los verdes y abundantes bosques de la región fueron presionados por la práctica del sistema de tumba y quema, las milpas y las huertas familiares poco a poco compartieron el espacio con los campos del cultivo comercial, con los matorrales y los pastizales que fueron apareciendo como resultado del uso intensivo que consumía la capa vegetal del suelo a causa de la introducción de una agricultura comercial que demandaba cada vez más materias primas para armar cigarros y puros.

Los informes redactados por los funcionarios de la Real Renta de Tabaco ilustran la presión experimentada por los bosques y la erosión de los suelos, al referir que el rendimiento agrícola de las tierras descendía al pasar de 856 libras 
por hectárea en 1780 a 628 libras por hectárea en 1805 y enfatizar que, al reducirse el rendimiento de la tierra, los cosecheros debían incrementar su inversión para mantener su nivel de producción (AGI, México, vol. 1406).

Debido a la constante producción de la hoja en la misma área de cultivo se provocó el agotamiento del suelo por desgaste de sus capas vegetales. Además, una vez que los suelos se hallaban erosionados, la forma de acceder a tierras fértiles fue desmontar áreas boscosas. Como se puede observar, el uso constante de la tierra sin un largo reposo tuvo efectos negativos, porque era necesario dejar en barbecho esas tierras al menos 20 años como se hacía en las plantaciones tabacaleras en la colonia inglesa de Maryland (Tatham, 1800: 118-129). Sin embargo, la política extractiva de las reformas borbónicas y las ambiciones de ganancia de los cosecheros de las villas impusieron un uso intensivo del suelo en la zona cálida de la Sierra de Zongolica.

Se considera necesario hacer notar que, el impacto ecológico tuvo un costo económico porque en la primera década del siglo XIX, los cosecheros orizabeños y cordobeses debieron invertir cada vez más para mantener los rendimientos obtenidos en el decenio de 1790 (AGN, Tabaco, vol. 44).

\section{CONCLUSIÓN.}

A lo largo del texto se busca demostrar que la perspectiva ambiental permite abordar un objeto de estudio desde diferentes enfoques como la historia política, económica y agraria. En este texto se presenta un estudio diferente y actual de un fenómeno ya analizado. Por ello, se considera que se realiza una pequeña contribución.

$\mathrm{Si}$ bien las investigaciones en torno a la Sierra de Zongolica y al "estanco del tabaco" no son nuevas, hasta ahora no se había hecho una propuesta de análisis desde la perspectiva ambiental para tal región y dicho proceso histórico. Hoy en día dadas las frecuentes contingencias ambientales enfrentadas se hace necesario conocer más y mejor los efectos provocados por las actividades humanas, como es el caso revisado a lo largo de este artículo. 
Una aproximación ecológica al estanco de tabaco en la Sierra de Zongolica, Veracruz...

Trabajar un problema histórico desde la perspectiva ambiental es un desafío, para encararlo se recurrió tanto a elementos conceptuales como a herramientas de análisis que se utilizan en la agronomía, la antropología social y la ecología.

El acercamiento al "estanco del tabaco" en la jurisdicción de Zongolica como mecanismo de control económico, permite observar que fue una estrategia de apropiación de recursos naturales por parte del sistema colonial español a través de sus representantes en Orizaba, así como los mercaderes de dicha villa y de la Ciudad de México, sin olvidar a las autoridades del cabildo de Zongolica. Ahora se propone un análisis cada vez más complejo que no sólo considere los aspectos económicos y sociales, sino que incorpore la perspectiva ambiental, ya que las diversas actividades humanas contienen dimensiones y repercusiones ambientales.

La aproximación a la interacción del hombre y la naturaleza permite advertir cómo ambos se influyen mutuamente. Por un lado, está el modo en que el hombre se adecúo a sembrar en las barrancas, cañadas y laderas en la tierra caliente de la Sierra de Zongolica, a conocer los tiempos de lluvia y de seca, así como los tipos de suelo útiles para los distintos cultivos, las técnicas para hacerlos más productivos según sus necesidades de consumo, sus representaciones culturales y valores. Por otro lado, se observa la forma en que el hombre incidió en la naturaleza, por ejemplo, a través de la agricultura.

Al realizar este primer acercamiento a las consecuencias ambientales del estancamiento de la siembra del tabaco en la Sierra de Zongolica, cuatro son las ideas que se pretenden remarcar. Uno, la siembra de la hoja influyó en la especialización agrícola de esta sierra en monocultivos comerciales, que a partir de entonces se sucedieron tras de sí ya que después del tabaco llegaron la caña de azúcar y el café. Dos, el establecimiento del monopolio del tabaco en la Sierra de Zongolica provocó que los agricultores del lugar descuidaran sus milpas y huertas por dedicarles su tiempo y esfuerzo a 
la siembra y cuidado de la hoja lo cual incidió en una reducción del cultivo de alimentos como el maíz, la calabaza y el chile.

Tres, la transformación ecológica más importante provocada por la introducción de la agricultura comercial a la Sierra de Zongolica, a través del tabaco fue la transformación del paisaje al transitar de uno donde había bosques y milpas a otro donde coexistieron menguadas milpas con bosques presionados por la tala, una agricultura comercial, así como matorrales y pastizales producto de la erosión del suelo; en las 1,560 ha abarcadas por los parajes donde se cosechó esta hoja tan demanda para el consumo local de los novohispanos.

Cuatro, en conjunto la política extractiva de las reformas borbónicas y la lógica económica de la ganancia desarrollada por los cosecheros de las villas de Orizaba y Córdoba, promovieron la deforestación de los bosques y el uso intensivo del suelo, fenómenos que a mediano plazo reclamaron la inversión de las ganancias obtenidas con la comercialización de la hoja, porque para mantener la productividad de la tierra se hizo necesario que los cosecheros gastaran cantidades importantes de dinero.

Aunque los datos obtenidos hasta ahora son exiguos para ser concluyentes si resultan ilustrativos para este primer acercamiento a las consecuencias ecológicas provocadas por la introducción del tabaco a la tierra caliente de la Sierra de Zongolica y permiten extender una invitación a profundizar el conocimiento de la historia agrícola de esta región.

\section{REFERENCIAS}

Aguirre, G. 1995. Los marqueses de la colina y el tabaco. Aguirre, G. Cuatro nobles titulados en la contienda por la tierra. (pp. 69136). México: CIESAS.

Álvarez, H. y M. Rodríguez. 1992. La apropiación de los recursos forestales en la tierra fría de la Sierra de Zongolica. Boege, E. y $\mathrm{H}$. Rodríguez (coords.). Desarrollo y medio ambiente en Veracruz. (pp. 159-168). México:

CIESAS/INECOL/Fundación

Friederich Ebert Stiftung. 
Boege, E. 2008. El patrimonio biocultural de los pueblos indígenas de México. Hacia la conservación in situ de la biodiversidad y agrodiversidad en los territorios indígenas. México: CDI/CONACULTA/INAH.

Céspedes, G. 1992. El tabaco en la Nueva España. Madrid: Real

Academia de Historia.

Funes, R. 2002. Azúcar, deforestación y medioambiente: los bosques de Cuba entre 1772 y 1926. Tesis de doctorado en historia, geografía y arte. Castellón de la Plana: Universitat Jaume I,

Galland, M. 2005. Los ingenieros militares españoles en el siglo XVIII. Cámara, A. (coord.). Los ingenieros militares de la monarquía hispánica en los siglos XVII y XVIII. (pp. 205-230). Madrid: Centro de Estudios de la Europa Hispánica.

Gallini, S. 2002. La rivoluzione del caffé in un agrosistema maya, Guatemala 1830-1902: una storia ambientale. Tesi di dottorato in storia dell'America, Genova: Universitá di Genova.

García, B. 2000. Regiones y paisajes de la geografía mexicana. Cosío, D. (coord.). Historia General de México. (pp. 235-306). México: COLMEX. y A. Gonzále (comp.).

1999. Estudios sobre historia y ambiente en América. Argentina, Bolivia, México, Paraguay. vol. I, México: El Colegio de México/Instituto Panamericano de Geografía e Historia.

González, J. s/f. Paso de Ovejas en el contexto del Veracruz central. Xalapa: mecanoscrito.

Grafensteins, J. 2001. Insurgencia y contrainsurgencia en el Golfo de México. 1812-1820. Guedea, V. (coord.). La independencia de México y el proceso autonomista novohispano, 1808-1824. (pp. 185228). México: UNAM/ Instituto Mora.

Hernández, L. (comp.). 2001. Historia ambiental de la ganadería en México. México: INECOL/Institut de Recherche pour le Développement.

Islas, M. 1990. Aspectos físicos y recursos naturales del estado de Veracruz. Xalapa: UV.

Jáuregui, L. 1993. Los fundamentos de la política fiscal. L. Ludlow y J. Silva (comps.). Los negocios y las ganancias, de la colonia al México moderno. (pp. 363-383). México: Instituto Mora/UAM.

Juárez, A. 2005. Veracruz y el nuevo orden económico, 17201820. Xalapa: IVEC. 
Martínez, M., y L. Ludlow (coords.). 2007. Historia del pensamiento económico: del mercantilismo al liberalismo. México: UNAM/ Instituto Mora.

McFarlane, A. 2008. Los ejércitos coloniales y la crisis del imperio español, 1808-1810. Historia Mexicana 39 (229), 229-285.

Melville, E. 1994. Plaga de ovejas. Consecuencias ambientales de la conquista de México. México: FCE.

Menegus, M. 1995. La participación indígena en los mercados del valle de Toluca a finales del periodo colonial. Silva, J., J. Grosso y C. Yuste (coords.). Circuitos mercantiles y mercados en Latinoamérica, siglos XVIII y XIX. (pp. 136-157). México: UNAM/ Instituto Mora.

Ortiz, J. 2006. Las compañías milicianas de Veracruz: del negro al jarocho. La construcción histórica de una identidad. Ulúa. Revista de Historia, Sociedad y Cultura 4 (8), 9-29.

Paso, F. 1988. La botánica entre los nahuas y otros estudios. México:

SEP.

Pietschmann, H. 1992. Agricultura e industria rural indígena en el México de la segunda mitad del siglo XVIII. Ouweneel, A. y C. Torales (comps.). Empresarios, indios y Estado. Perfil de la economía mexicana (siglo XVIII). (pp. 115-138). México: Universidad Iberoamericana.

Ponce, R. y H. Cerda. 1981. La regionalización del ambiente basada en la fisiografía y su utilidad en la producción agropecuaria. Hernández, E. (coord.). Agroecosistemas de México. Contribuciones a la enseñanza, investigación y divulgación agrícola. 2a ed. (pp. 4169). Chapingo: Colegio de Posgraduados.

Quiroga, J. 1779. Descripción de Veracruz y su provincia, tratado sobre la cultura y preparaciones del tabaco en Córdova y Orizaba, por el factor de tabaco en aquella capital. Manuscrito.

Reyes, L. 1962. La tenencia de la tierra en Zongolica. Xalapa: UV.

Ribera Carbó, E. 2002. Herencia colonial y modernidad burguesa en un espacio urbano. El caso de Orizaba en el siglo XIX. México: Instituto Mora.

Rodríguez, M. 1993. Grupos domésticos y organización ceremonial en Atlahuilco. Estrategias de subsistencia y participación comunitaria. Tesis de maestría en antropología social. Xalapa: CIESAS. . 2003. Ritual, identidad y procesos étnicos en la Sierra de Zongolica, Veracruz. México. CIESAS. 


\section{Flores para la}

tierra. Paisaje y cultura en la Sierra de Zongolica. Córdova, R. (coord.). Atlas cultural del estado de

Veracruz. t. III. (pp. 67-88). México. Gobierno del Estado de Veracruz/UV.

Rojas, T. 1988. Las siembras de ayer. La agricultura indígena del siglo XVI. México: SEP/ CIESAS.

Silvestre, J. 2004. Los cosecheros de tabaco de Orizaba en las postrimerías coloniales, 1800-1812. Xalapa: Monografía de licenciatura en historia. UV.

Soluri, J. 2013. Culturas bananeras. Producción, consumo y transformaciones socioambientales. Bogotá: Universidad Nacional de Colombia.

Tanck, D. 2005. Atlas ilustrado de los pueblos indios: Nueva España 1800. México: CDI/COLMEX/EI Colegio Mexiquense/Fomento Cultural Banamex.

Tatham, W. 1800. An Historical and Practical Essay on the Culture and Commerce of Tobacco. London: Vernor and Hood.

Tortolero, A. (coord.). 1996. Tierra, agua y bosques: historia y medio ambiente en México. México:

FCE/Universidad de Guadalajara.

Valle, G. 1996. Distribución de la población en el espacio urbano de Orizaba en 1791. Blázquez, C., C.
Contreras y S. Pérez (coords.). Población y estructura urbana en México, siglos XVIII y XIX. (pp. 129-151). México: Instituto Mora/UAM. 1993. El camino de Orizaba y los problemas para financiar su conservación, 17591795. Ludlow, L. y J. Silva (comps.). Los negocios y las ganancias, de la colonia al México moderno. (pp. 176-191). México: Instituto Mora/UAM.

$$
\text { 2008. El }
$$

monopolio del tabaco en Veracruz durante la guerra de independencia. Ortiz, J. (coord.). Revisión histórica de la guerra de independencia en Veracruz, 1810-1825. (pp. 53-71). México: Gobierno del Estado de Veracruz/UV.

Watsuji, T. 2006. Antropología del paisaje. Climas, culturas y religiones. Salamanca: ediciones Sígueme.

Whitmore, T. 2003. Paisajes agrícolas de Mesoamérica de la era de contacto o cómo mentir con mapas. Tiempos de América. 7 (10), 73-85. 